\title{
LEYES CIENTÍFICAS Y PREDICCIÓN EN CIENCIAS SOCIALES: UNA APROXIMACIÓN AL CASO DE LA ECONOMÍA*
}

\author{
Gabriel Francisco Guzmán Castro** \\ Recibido: diciembre 09 de 2011 • Aceptado: diciembre 11 de 2012
}

\section{RESUMEN}

Entre las discusiones vigentes más importantes en la filosofía de la ciencia figura aquella concerniente a la posibilidad de que las ciencias sociales expliquen y predigan, mediante leyes causales, tal y como lo hacen algunas ciencias naturales, en especial la física. Este ensayo busca mostrar (a) que pese a las expectativas, la economía no ha logrado ser la primera de las ciencias sociales en contar con leyes de capacidad explicativa-predictiva creciente y (b) que existe algún acuerdo en cuanto a que lo anterior ocurre porque los economistas han fallado en la definición de términos adecuados para formular las generalizaciones de su investigación empírica. Para alcanzar sus propósitos, el escrito brinda un balance general y un análisis crítico de la evolución del esfuerzo de la teoría económica dominante por asemejarse a las ciencias naturales en cuanto a su método. La revisión de una serie de argumentos provenientes de diferentes áreas del conocimiento permite mostrar cómo la economía habría fracasado en su intento de establecer las unidades de análisis básico con las cuales dar forma a sus teorías.

\section{PALABRAS CLAVE}

Ciencias sociales, leyes científicas, predicción, filosofía de la ciencia, filosofía de la economía, metodología de la economía.

\section{CLASIFICASIÓN JEL}

B00, B21, B40, B41

\section{CONTENIDO}

Introducción; 1. La metodología de la economía según Milton Friedman; 2. Algunos elementos para la discusión provenientes de la filosofía de la ciencia de Ernest Nagel; 3. Algunas consideraciones más recientes a propósito del debate; 4. ¿Una o dos ciencias?; 5. Conclusiones; Bibliografía.

\footnotetext{
Este artículo de investigación es producto de una serie de reflexiones surgidas durante la realización de la tesis titulada El átomo de la realidad social y la ontología de la realidad institucional para John Searle, desarrollada por el autor para optar al título de Magister en Filosofía en la Maestría en Filosofía de la Universidad Nacional de Colombia, Bogotá, Colombia. Una primera versión del mismo fue presentada en el First Seminar in Austrian and Heterodox Economics llevado a cabo en Bogotá entre el 9 y 11 de agosto de 2011 y organizado por el Grupo de Investigación en Macroeconomía y Política Económica (Macrópolis) de la Universidad Nacional de Colombia.

** Economista, Universidad del Tolima, Ibagué, Colombia. Magíster en Filosofía, Universidad Nacional de Colombia, Bogotá, Colombia. Docente de tiemplo completo del Programa de economía de la Facultad de ciencias Económicas y Administrativas de la Universidad de Ibagué, Ibagué, Colombia. Miembro del Grupo de Investigación UNIDERE. Correo electrónico: gabriel.guzman@unibague.edu.co.
} 


\section{SCIENTIFIC LAWS AND PREDICTION IN SOCIAL SCIENCES: AN APPROCACH TO THE CASE THE ECONOMY \\ ABSTRACT}

Among the most important current discussions within the philosophy of science, it is found the one concerning the possibility that social sciences explain and predict by casual laws, as some natural sciences do, especially physics. This paper seeks to show (a) that despite expectations, economics has not been able to be the first of the social sciences to count with explanatory-predictive and growing capacity laws and (b) that there is an agreement that the above occurs because economists have failed to define adequate terms for the formulations of the generalizations of their empiric evidence. To achieve this purpose, this brief provides a general balance and a critical analysis of the evolution of the efforts done of the dominating economic theory to resemble the method of natural sciences. The conclusion of a number of arguments coming from different areas of knowledge can show how the economy would have failed in its attempt to establish basic analysis units with which to shape its theories.

\section{KEY WORDS}

Social sciences, scientific laws, prediction, science philosophy, philosophy of economics, economic methodology.

\section{JEL CLASSIFICATION}

B00, B21, B40, B41

\section{CONTENT}

Introduction; 1. Economic methodology according to Milton Friedman; 2. Some elements for the discussion of science philosophy of Ernest Nagel; 3. Some recent consideration concerning the debate; 4. ¿One or two sciences? 5. Conclusions; Bibliography.

\section{LEIS CIENTÍFICAS E PREDIÇÃO EM CIENCIAS SOCIAIS: UMA APROXIMAÇÃO AO CASO DA ECONOMÍA \\ RESUMO}

Entre as discussões vigentes mais importantes ao interior da filosofia da ciência figura aquela concernente à possibilidade de que as ciências sociais expliquem e predigam mediante leis causais, tais como o fazem algumas ciências naturais, em especial a física. Este ensaio procura mostrar (a) que pese às expetativas, a economia não tem conseguido ser a primeira das ciências sociais em contar com leis de capacidade explicativo-preditiva crescente e (b) que existe algum acordo enquanto a que o anterior ocorre porque os economistas têm falhado na definição de termos adequados para formular as generalizações de sua pesquisa empírica. Para atingir seus propósitos, o escrito fornece um balance geral e uma análise crítico da evolução do esforço da teoria económica dominante por assemelhar-se às ciências naturais enquanto ao seu método. A revisão de uma serie de argumentos provenientes de diferentes áreas do conhecimento permite mostrar como a economia teria fracassado no seu intento de estabelecer as unidades de análise básica com as quais darem forma às suas teorias.

\section{PALAVRAS CHAVE}

Ciências sociais, leis científicas, predição, filosofia da ciência, filosofia da economia, metodologia da economia.

\section{CLASIFICAÇÃO JEL} B00, B21, B40, B41

\section{CONTEÚDO}

Introdução; 1. A metodologia da economia segundo Milton Friedman; 2. Alguns elementos para a discussão provenientes da filosofia da ciência de Ernest Nagel; 3. Algumas considerações mais recentes com propósito do debate; 4. ¿Uma ou duas ciências?; 5. Conclusões; Bibliografia. 
Leyes científicas y predicción en ciencias sociales: una aproximación al caso de la economía

\section{INTRODUCCIÓN}

A partir del siglo XVI las ciencias naturales iniciaron un período de rápida expansión marcado por una capacidad explicativa-predictiva cada vez mayor, hecho que inspiró a un número creciente de estudiosos de los fenómenos sociales para quienes el camino recorrido por las ciencias de la naturaleza era la ruta correcta hacia la construcción de un saber, del hombre y su sociedad, digno de ser denominado ciencia. Más de un siglo y medio después de que los pioneros en tal línea de pensamiento entregaran al público sus obras -A. Comte (1830-1842/1864) y J. S. Mill (1843)-, los balances no son homogéneos, pero concuerdan en que una ciencia social capaz de explicar y predecir, tal y como lo hace la física o la química, no ha sido construida aún. La economía, rama del conocimiento social de la cual se esperaba el más acelerado progreso hacia el éxito de las ciencias naturales dista de haber logrado tal objetivo. Consecuencia de ello es el surgimiento de dos grandes posiciones antagónicas: (a) una que confía en que de manera eventual, conforme avance su construcción teórica y fortalecimiento empírico, las ciencias sociales se acercarán al ideal representado por la física y (b) otra que defiende que este fin no solo es inalcanzable, sino que, además, ir en su búsqueda puede resultar contraproducente.

El presente ensayo es un abordaje al mencionado debate, el cual, dadas las proporciones de la discusión, se concentra en mostrar cómo parece existir un acuerdo en que, tal y como lo detecta Nagel (1961) -sección 2-, dos aspectos: (a) la naturaleza de los términos -o distinciones- en que se formulan las generalizaciones de la investigación social empírica y (b) la dificultad para fijar casos puros en ciencias sociales, han incidido de forma considerable para que, por ahora, no haya sido posible formular leyes científicas como tal ni hacer predicciones tan certeras en ciencias sociales.

Si bien, como se puede apreciar en la sección que viene a continuación Milton Friedman (1953), en The Methodology of Positive Economics, ve la economía como un caso palpable de una ciencia social en proceso de convertirse en una ciencia "dura" -esto es, un cuerpo teórico conformado, entre otros elementos, por leyes aceptadas por la mayor parte de la comunidad científica pertinente-, el balance presentado en la sección 3.1 arroja como resultado que -sesenta años después de haber sido publicado el que para Daniel Hausman (2007, p. 180) es el trabajo más influyente del siglo XX en metodología de la economía- los vaticinios de Friedman (1953) distan de haberse cumplido!

\footnotetext{
En este caso, y a menudo en adelante, las referencias a la economía y a la teoría económica neoclásica se hacen de manera indistinta. Lo anterior no resulta ser lo más indicado por cuanto implica desconocer la coexistencia de un número considerable de corrientes de pensamiento económico. No obstante, en
} 
Al respecto, el filósofo de la economía Alexander Rosenberg (1983 y 1992) ofrece argumentos interesantes que apoyan la hipótesis, coincidente con parte de lo planteado por Nagel (1961), según la cual el uso de términos inadecuados para formular sus generalizaciones habría conducido a la economía neoclásica al fracaso en cuanto a la enunciación de verdaderas leyes científicas.

En el escenario propuesto, permanece abierta la pregunta acerca de la condición epistémica tanto de la economía, en particular, como de las ciencias sociales, en general. Sobre esto último, en las secciones 4.1 y 4.2 son descritas dos posiciones que señalan rumbos que podrían llegar a tomar en el futuro las ciencias del comportamiento humano. En el primer caso, se ofrece un esbozo de la perspectiva mantenida por Tooby y Cosmides (1992), la cual se considera una alternativa teórica y metodológica que puede ser vista como continuadora de la tradición en ciencias sociales del proyecto inaugurado por los padres del positivismo. Más en concreto, para estos dos autores los desarrollos en biología evolutiva establecieron las bases para que, de forma progresiva, se cierre la brecha que separa a ciencias naturales y sociales. Esta propuesta, al igual que otras tantas inspiradas en la idea de la unificación de las ciencias, se conserva hasta la fecha apenas como una posibilidad más, ya que no se cuenta aún con evidencia satisfactoria, a favor o en contra, que permita fijar una posición definitiva al respecto.

Para contrastar la tradición recién nombrada, hacia el final del documento se presenta parte del análisis de Peter Winch (1958). Este filósofo, influenciado por las ideas del célebre pensador austriaco Ludwig Wittgenstein (1953), brinda argumentos sugestivos a favor de la hipótesis de que un abismo insalvable separa a las ciencias naturales de las sociales. Esto tendría, tal y como podrá leerse más adelante, implicaciones profundas en las aspiraciones de las ciencias de la sociedad -incluida la economía- de lograr hacer predicciones por medio de leyes causales -tal y como lo contempló Mill (1843) permeado por los avances en las ciencias naturales de su época y la noción humeana de causalidad-.

Al final, se espera mostrar que este gran y álgido debate sigue abierto como consecuencia de que ninguna posición en particular ha sido capaz de imponerse con claridad. Ante un escenario tan complejo y difícil de esclarecer, resulta destacable que permanezca vigente la idea de que la posibilidad de que las ciencias sociales, como la economía, lleguen a ostentar resultados comparables a los de las de ciencias naturales, como la física, depende del éxito en la identificación de unidades de análisis apropiadas para la formulación de sus teorías.

la medida en que son muy escasas las alusiones que se hacen en este trabajo a otras tradiciones, para simplificar, a menos que se aclare algo diferente, se mantendrá tal homologación de los términos. 
Leyes científicas y predicción en ciencias sociales: una aproximación al caso de la economía

\section{LA METODOLOGÍA DE LA ECONOMÍA SEGÚN MILTON FRIEDMAN}

En A System of Logic, J. S. Mill (1843) plantea que es factible que las ciencias sociales expliquen mediante leyes causales, tal y como lo hace con especial éxito la física. La perspectiva milliana es un caso paradigmático de aquella línea de pensamiento para la cual es posible que las ciencias de la naturaleza y las de la sociedad se unifiquen al compartir teorías y metodología ${ }^{2}$. De forma similar, tal y como se aprecia en su reconocido artículo -The Methodology of Positive Economics-, M. Friedman (1953) confía, en que la brecha que separa a las ciencias sociales de las naturales se puede cerrar. En opinión de este autor, la economía sería un caso palpable de una ciencia social en pleno proceso de convertirse en, valga la expresión algo coloquial, una ciencia dura.

En su ensayo, Friedman (1953) comienza por distinguir entre economía positiva -ocupada de lo que es- y normativa -dedicada al deber ser-. La primera tendría como objetivo primordial proveer un sistema de generalizaciones que pueda aplicarse a predicciones correctas acerca de las consecuencias de cambios circunstanciales. Al respecto, Friedman (1953, p. 647) indica: "Su desempeño [-de la economía positiva-] debe ser juzgado por la precisión, alcance, y conformidad con la experiencia de las predicciones que arroja". Desde este punto de vista, queda claro, la predicción ocupa un lugar central en la labor científica. En relación con esto último, aunque más ligado a la construcción teórica como tal, y a propósito de la comprobación de hipótesis, es usual que como explicación de un fenómeno particular se cuente con un número de hipótesis que tienda a ser infinito. Ante una cantidad tal de respuestas tentativas, todas consistentes con la evidencia disponible, surge la duda respecto a cuál de ellas preferir. Entre hipótesis alternativas, afirma Friedman (1953, p. 650), nociones como las de simpleza -menor cantidad de conocimiento inicial requerido para efectuar una predicción-y fertilidad -predicciones más precisas, con mayores alcance y posibilidad de apertura de nuevas líneas de investigación- surgen como varas de medida que permitirían elegir.

Contra el argumento del carácter no experimental de la economía, usado con frecuencia para poner en entredicho la idea de la posibilidad de generalizaciones universales y predicciones confiables en ciencias sociales, Friedman (1953, p. 651) insiste en que no habría una distinción tajante entre ciencia natural y ciencia social. Lo anterior porque: (a) en algunas ciencias naturales, como en la astronomía, la experimentación es ajena; y (b) la distancia entre experimentación controlada -como en la física-y experiencia no controlada como en economía- es apenas de grado. En el primer caso el control nunca es total y en el segundo jamás está ausente por completo3.

2 En la sección 4.2 hay una aproximación a estas ideas de Mill (1843).

3 Con esto se mostraría de acuerdo el filósofo de la ciencia E. Nagel (1961, p. 413-415), quien, de hecho, agregaría más razones para considerar que en muchos aspectos el parecido de las ciencias naturales y 
Hasta acá, es posible afirmar que para Friedman los problemas propios de la economía no serían de índole metodológica. Este pensador confía en la abundancia y valor concluyente de la información factible de ser acumulada, pero, en tanto evidencia, reconoce la dificultad para su interpretación, la cual puede venir acompañada de obstáculos para el logro de un acuerdo amplio sobre conclusiones justificadas por la evidencia disponible y la lenta y difícil -en realidad nunca definitiva- desaparición de hipótesis no exitosas. En ocasiones, Friedman (1953, p. 651), señala que la evidencia recogida en la experiencia es tan "directa, dramática, y convincente" que iguala a la proporcionada por cualquier experimento controlado ${ }^{4}$.

Otra característica de la teoría económica -analizada por Rosenberg (1992) y Bergmann (2005) más adelante-, que al criterio de Friedman (1953, p. 652) no constituye una limitante, puesto que no afectaría su pertinencia, es la falsedad de los supuestos de sus hipótesis. Así, dado que, en su opinión, la importancia de una hipótesis se deriva del hecho de que explique mucho al hacer abstracción de las circunstancias complejas junto a las cuales se hallan los elementos comunes y cruciales, una hipótesis tiene que ser falsa, desde un punto de vista descriptivo, en sus supuestos.

Una buena hipótesis, menciona el economista de Chicago, puede sostener que, por ejemplo, las hojas en un árbol se distribuyen como si buscaran maximizar los rayos de luz que chocan sobre su superficie. Está claro que las hojas no efectúan cálculos maximizadores, pero al suponerlo, manifiesta, es posible comprender muchos casos particulares y predecir otro tanto. Un billarista, añade, no resuelve complejas fórmulas antes de ejecutar sus jugadas, pero se puede asumir que actúa como si lo hiciera y, de tal forma, resulta factible comprender sus jugadas pasadas y esperar alguna norma de comportamiento para sus futuras acciones. Así, para Friedman (1953, p. 656):

No hay más que un paso de estos ejemplos [de las hojas y el billarista] a la hipótesis económica de que bajo un rango amplio de circunstancias las firmas individuales se comportan como si ellas estuvieran buscando racionalmente maximizar sus ingresos esperados [...] y tuvieran conocimiento completo de los datos requeridos para tener éxito en su intento; esto es, como si conocieran las funciones de costo y demanda relevantes, calculando el costo marginal y la renta marginal para todas las acciones abiertas para ellos, y llevando cada línea de acción al punto en el cual el costo marginal y la renta marginal relevantes fueran iguales.

las sociales es mayor del que se sospecha y que las leyes y predicciones exactas salidas del laboratorio, son menos frecuentes de lo que se asume.

4 Para Friedman (1953, p. 651), un ejemplo elocuente sería el comportamiento de la inflación. Para él, en este caso, la hipótesis de que un incremento sustancial en la cantidad de moneda, en un periodo de tiempo relativamente corto, se ve acompañado por un incremento considerable en los precios, contaría con evidencia "dramática" y la cadena de razonamientos requerida para su interpretación sería relativamente corta. 
Leyes científicas y predicción en ciencias sociales: una aproximación al caso de la economía

El hombre de negocios no resolvería de manera literal el sistema de ecuaciones simultáneas, tal y como el economista las realiza para expresar sus hipótesis, pero al asumir que sí lo hace pareciera viable dar cuenta de, y predecir con cierta facilidad, la mayor parte de sus actos. De este modo, Friedman (1953) descarta que factores tales como la falsedad de los supuestos o las dificultades experimentales -los cuales suelen ser identificados como limitantes para el fortalecimiento de la teoría económica- mantengan a la economía incapaz de explicar y predecir por medio de leyes científicas.

\section{ALGUNOS ELEMENTOS PARA LA DISCUSIÓN PROVENIENTES DE LA FILOSOFÍA DE LA CIENCIA DE ERNEST NAGEL}

Una de las mayores conclusiones de Nagel (1961) -The Structure Of Science: Problems In The Logic Of Scientific Explanation- es que, de manera consistente con lo dicho por Friedman (1953), no se dispone de evidencia conclusiva que permita negar la posibilidad de que las ciencias sociales logren éxitos como los de las ciencias naturales. Este autor enfrenta posiciones que desde diferentes ángulos sostienen lo contrario; en particular, respecto a la probabilidad de que sean formuladas leyes científicas de la sociedad. En esta sección, se dará un vistazo a los contraargumentos ofrecidos por Nagel (1961) frente a tales planteamientos. No obstante, cabe precisar, se enfatizará en la existencia de dos características notables de las ciencias sociales, por cuanto, como se intentará demostrar, ellas se mantienen hasta la fecha como fuertes limitantes para alcanzar este objetivo. Tales son: (a) la naturaleza de los términos -o distinciones- en que se formulan las generalizaciones de la investigación social empírica, y (b) la imposibilidad de fijar casos puros en ciencias sociales.

Como bien señala Nagel (1961, p. 453-454), la mayoría de las generalizaciones establecidas a partir de la investigación empírica en ciencias sociales son de carácter estadístico; es decir, antes que poseer un alcance universal, abarcan apenas una fracción -"especificada más o menos precisamente"- de los casos correspondientes a un fenómeno particular, si bien las generalizaciones estadísticas no son exclusivas de las ciencias sociales y se encuentran también en ramas de las ciencias naturales como la meteorología, la fisiología y la etología, sí predominan en aquellas.

A menudo, se sostiene que la naturaleza estadística de las generalizaciones derivadas de estudios sociales empíricos obedece a dos razones: (a) el elevado número de variables involucradas y (b) el carácter libre - por tanto variable- de la voluntad humana5. Sin embargo, de acuerdo con Nagel (1961, p. 454) la complejidad no es

\footnotetext{
Para esta última existe una variante según la cual las acciones humanas dependen de la interpretación de estímulos externos. Así, diferencias en el desarrollo personal y en las dotes innatas de cada individuo conducirían a interpretaciones -previas a la acción- igualmente diversas.
} 
exclusiva de las ciencias sociales; también está presente -y en altísimo grado- en fenómenos físicos y biológicos que, a pesar de ello, han podido ser explicados mediante leyes generales. Asimismo, la existencia de múltiples interpretaciones sobre algún aspecto social no tiene que ser por necesidad incompatible con la aparición de leyes científicas en al menos una de tales interpretaciones. Ninguna de las dos razones explicaría, entonces, el porqué del predominio de las generalizaciones estadísticas en las ciencias sociales.

En su lugar, para Nagel (1961) existirían dos aspectos metodológicos más relevantes. El primero (a) se relaciona con la naturaleza de los términos -o distinciones-en que se formulan las generalizaciones de la investigación social empírica. En ciencias sociales los términos usados suelen asimilarse a conceptos empleados de forma laxa en la cotidianeidad -por ejemplo: sentimiento de privación, estado anímico, y rol-. En opinión de Nagel (1961, p. 419, 455 456), estos presentan cierta indeterminación, codifican distinciones poco refinadas y abarcan entes menos homogéneos con respecto a los de las ciencias naturales ${ }^{6}$.

La posibilidad de llegar a formular generalizaciones universales en ciencias sociales pasa por la elaboración de clasificaciones más precisas, tan solo evaluables mediante ensayos concretos. Ahora bien, anota Nagel (1961, p. 456), definir el grado de generalidad adecuado para los problemas investigados, así como el nivel de análisis pertinente, no es fácil. Características físicas y fisiológicas tendrían que ser introducidas. Empero, niveles muy precisos de detalle -que podrían llegar a contemplar aspectos (¿cuántos, hasta qué grado de profundidad?) como: estructura ósea, niveles de calcio acumulado en las coyunturas, composición química de la sangre, distribución espacial de los filamentos nerviosos, etc.- pueden conducir a leyes científicas cuya especificidad sería tal, que no tendrían mayor valor frente a leyes más amplias -y por ende, cercanas al interés general, habitual en la investigación social-, aun cuando apenas fuesen generalizaciones estadísticas.

El segundo aspecto metodológico (b) obedece a que, por lo común, los términos de una ley general corresponden a idealizaciones de propiedades observadas. Esto se entiende mejor con una mirada a las ciencias naturales. En estas, la posibilidad de formular leyes científicas se encuentra atravesada por la definición de condiciones ideales, la identificación de casos puros y el responder por las discrepancias entre lo sostenido por la ley y los resultados observacionales. En la física, por ejemplo, es

6 A manera de ejemplo, Nagel (1961, p. 456) muestra cómo analizar la conductividad eléctrica de algunos materiales en función de la temperatura, con miras a formular generalizaciones sería poco fructífero si la única distinción hecha resulta ser aquella entre metales y no metales. Se puede apreciar que la distinción es insuficiente y, dadas las diferencias entre tipos de metales, cualquier intento de generalización apenas llegaría a ser estadística. 
Leyes científicas y predicción en ciencias sociales: una aproximación al caso de la economía

habitual la formulación de leyes para casos ideales. Una ley así enuncia alguna relación de dependencia que se presume válida solo para una condición límite. Al momento de analizarse una situación particular, se deben formular supuestos o postulados adicionales que puedan cerrar la brecha entre la situación ideal y el caso concreto.

En ciencias sociales esta estrategia es poco frecuente. Un intento -pero con escasos avances en cerrar la brecha ley-realidad-sería, cabe destacar, el de la teoría económica neoclásica, en la que se habla a menudo de competencia perfecta o de maximización de la utilidad por parte de los agentes económicos. Para Nagel (1961, p.418-419), el limitado progreso a la hora de formular leyes generales en economía no obedecería tanto al uso de la estrategia de recurrir a la formulación de casos ideales como:

[... ] a las nociones teóricas específicas empleadas en esos intentos, [y] a las dificultades para discernir de qué manera es necesario modificar las enunciaciones que utilizan nociones 'ideales' a la luz de las circunstancias especiales que se presentan en las situaciones sociales concretas a la cuales pueden aplicarse dichas formulaciones?

En cuanto a la predicción, el éxito alcanzado en este sentido por las ciencias naturales se encuentra ligado de manera muy estrecha a la existencia de leyes causales de la naturaleza. Respecto al caso de las ciencias sociales, Nagel (1961, p. 537) considera que no existe nada que permita sostener, ni desde el punto de vista de la teoría, ni de hecho, que las acciones humanas sean en lo fundamental imprevisibles. Este autor cuestiona dos situaciones extremas: una es la pretensión de predecir cada detalle del futuro del hombre; la otra es la absoluta incapacidad para afirmar algo sobre el futuro humano. Hay aspectos puntuales, como los horarios de apertura de las instituciones públicas el día de mañana, los cuales pueden ser previstos con bastante precisión. Otros casos, como el ganador de las próximas elecciones presidenciales, escapan a las posibilidades de un pronóstico exacto; no obstante, es dable excluir un número amplio de posibilidades lógicas y, pese a que existe un margen considerable de libertad de elección en las acciones humanas, las opciones y acciones reales caen dentro de límites bien definidos ${ }^{8}$.

7 Nagel (1961, p. 417) considera equivocado suponer que la presencia de diferencias importantes en las características y la conducta de una clase de sistemas excluya la posibilidad de que haya un esquema común de relaciones subyacentes en esas diferencias, y que estas no puedan ser entendidas al apelar a una teoría única. El autor muestra cómo fenómenos tan disímiles como una tormenta eléctrica, los movimientos de una brújula y la aparición de un arco iris, a pesar de la apariencia, pueden ser todos explicados por la teoría electromagnética, entendida como la teoría general capaz de abarcar cada uno de los casos especiales. Sin embargo, por lo pronto, la construcción de una teoría social así es apenas una posibilidad lógica -Tooby y Cosmides (1992), sección 4 de este ensayo, consideran que su propuesta lo podría materializar-.

8 Como hecho curioso, en el ejemplo que proporciona Nagel (1961, p. 537) para ilustrar este punto afirma: "Sin duda, no podemos predecir con ninguna certidumbre quien será el próximo presidente de los Estados Unidos. Pero si consideramos las actitudes corrientes de los norteamericanos hacia los problemas domésticos y extranjeros, así como el 
Por lo dicho, Nagel (1961, p. 537) concluye que no todo lo que resulta viable para la lógica es posible en la historia para un momento y una sociedad determinados. Ahora bien, ¿cuál es la línea que separa lo viable para la lógica de lo posible para la historia? Seguro que no se cuenta de momento con la respuesta, pero no sobra llamar la atención acerca de la manera como la historia se halla colmada de hechos inesperados -los resultados de la predicción formulada por el propio Nagel (1961) en la nota al pie número 8 son bastante elocuentes-. Por su parte, se comparte la posición de este autor en cuanto a que las explicaciones históricas y las predicciones de sucesos futuros son "casi invariablemente imprecisas e incompletas". Ahora bien, es la utilidad de predicciones imprecisas e incompletas -que depende del grado de imprecisión y parcialidad-, y no su posibilidad, aquello que resulta ser en verdad digno de análisis.

\section{ALGUNAS CONSIDERACIONES MÁS RECIENTES A PROPÓSITO DEL DEBATE}

\subsection{Un balance más cercano}

Con más de medio siglo de haber salido a la luz los antes citados trabajos de Friedman (1953) y Nagel (1961), y en el contexto vigente de una nueva fase recesiva en buena parte del mundo desarrollado, se pone a la orden del día la evaluación del desempeño de la economía. Influenciado por otra crisis económica, la denominada Crisis del petróleo ocurrida en la década del setenta, Alexander Rosenberg (1983) pregunta con el título de su artículo: ¿Si la economía no es ciencia, qué es? En este escrito, Rosenberg (1983, p. 661) replantea una posición mantenida por él mismo con anterioridad, cercana a la adoptada por Friedman (1953), según la cual la teoría económica sería un cuerpo conceptual coherente conformado por proposiciones causales generales a la espera de constituirse en leyes científicas. No obstante, valga decir, ya desde aquel entonces este filósofo de la economía comenzó a recalcar, entre otros problemas, la "debilidad predictiva" de esta rama del conocimiento de la sociedad.

Desde el punto de vista de Rosenberg (1983, p. 661), tras perfilarse como una teoría con capacidad explicativa-predictiva a la medida de la ciencia y de dominar el panorama intelectual durante el periodo de mayor crecimiento económico bajo

alineamiento actual de los poderes del mundo, tenemos buenas bases para confiar en que habrá una elección presidencial el próximo año bisiesto, que ningún partido político importante nombrará a un comunista y que el candidato triunfante no será ni una mujer ni un negro". Su libro fue publicado en 1961; el 20 de enero de ese mismo año asumió la presidencia J. F. Kennedy, quien fue sucedido por L. B. Johnson, no en las elecciones del siguiente año bisiesto (1964), sino el 22 de noviembre de 1963, luego de que Kennedy fuera asesinado. Ni esto, ni que en 1974 R. Nixon dimitiría -por esto el presidente número 38 tampoco asumió el cargo tras unas elecciones celebradas en año bisiesto-, ni que el presidente número 44 sería un afroamericano, pudo haber sido predicho por Nagel (1961). 
Leyes científicas y predicción en ciencias sociales: una aproximación al caso de la economía

el capitalismo -1945 a 1973-, la macroeconomía keynesiana se tropezó con situaciones inesperadas como la coexistencia de niveles altos de inflación y desempleo y la inoperancia de -su fórmula terapéutica- la política fiscal, que provocó un retorno -y no el surgimiento de una tercera opción teórica- a la microeconomía neoclásica que se pensaba remplazada por aquella, tras el colapso de la Gran depresión?

Para Marqués (2003, p. 35), a partir de la segunda mitad del siglo XX, se ha manifestado tanto en las ciencias en general, como en la economía en particular, un sostenido declive del papel atribuido a la experiencia empírica en la adquisición y desarrollo del conocimiento que ha conducido a que epistemólogos de la economía importantes, como Hausman (1998), reconozcan que no es clara la manera como la experiencia podría confirmar la teorías básicas en microeconomía y a que no popperianos, como Hands (1993), y neo-popperianos, como Klant (1994), postulen que las teorías económicas son irrefutables. Barbara Bergmann (2005, p. 53), por su parte, describe un panorama de acuerdo con el cual, "[e]n economía [...] la evidencia que ha sido recogida hasta ahora sobre los asuntos más importantes es escasa, indirecta, difícil de interpretar, y no ha servido bien para proveer respuestas que aclararían las controversias". Esto sería cierto para la macroeconomía en asuntos como el desempleo, la inflación y el comercio exterior. La misma Bergmann (2005, p. 60) brinda una extensa lista de tópicos que el economista "neokeynesiano" N. Gregory Mankiw (2000) -profesor de Harvard y asesor económico del gobierno Bush entre 2003 y 2005-, reconoce, en su popular libro de texto de macroeconomía, como objeto de desacuerdo: las diferencias de las tasas de ahorro e inversión entre países, el grado de respuesta -importante en política económica- del ahorro privado a los incentivos gubernamentales, los determinantes del progreso tecnológico, las tendencias de la tasa de desempleo -que "permanecen en el misterio"-, las causas de la Gran depresión, los modelos de oferta agregada, la evaluación de la política económica y las fluctuaciones económicas.

\subsection{El porqué de los resultados: dos posibles (pero no únicas) respuestas}

Junto con Friedman (1953) y Nagel (1961), las dos perspectivas que se exponen a continuación coinciden en una valoración alta de la capacidad predictiva, que debe alcanzar una ciencia social como la economía, como requisito para merecer el título de ciencia. Difieren, no obstante, en la identificación de las causas y en las salidas

\footnotetext{
9 Parecería más adecuado hablar de neoliberalismo, una mezcla de economía neoclásica y liberalismo decimonónico, al cual se acusa de haber dado forma a la actual crisis. Bien vale afirmar que en el escenario vigente, en la academia y las instituciones multilaterales y estatales no se avizora una propuesta alternativa a las teorías neoclásica y keynesiana -en su momento promovidas para luego ser revaluadas-.
}

Semestre Económico, volumen 16, №. 33, pp. 99-126 • ISSN 0120-6346, enero-junio de 2013, Medellín, Colombia 
propuestas a los problemas vinculados al escaso poder explicativo-predictivo de la ciencia económica.

\subsubsection{Trabajo de campo frente a trabajo de escritorio}

Bergmann (2005) coincide con Rosenberg (1983) en lo negativo del balance y en la convicción de la necesidad de construir una ciencia económica que explique y prediga bien. Para Bergmann (2005, p. 53), pasados más de doscientos años desde la publicación de La riqueza de las naciones de Smith (1996), todavía no se cuenta con una ciencia confiable al momento de prevenir o corregir la ocurrencia de los principales fallos de la economía. Sin embargo, difiere en la ubicación de las causas. Además de la dificultad propia del estudio de una economía nacional, esta autora señala el impacto negativo de la ausencia de observación directa y recolección de datos por los mismos economistas. La teoría económica sería, entonces, creada en su mayoría sin inspiración o validación por la observación de primera mano del funcionamiento económico real. Habría pocos contraejemplos, de los que solo unos cuantos han salido del laboratorio -con estudiantes que se prestan como actores económicos- para tener contacto directo con el verdadero mundo de los negocios.

Esto último sería uno de los dos hábitos metodológicos que, de acuerdo Bergmann (2005, p. 54), habrían conducido a los pobres resultados y a la "influencia de factores extra científicos en la creación y aceptación de teorías particulares [en economía]". El otro se trataría de la carencia de una conexión rigurosa entre macroeconomía -y su estudio de la economía como un todo-y una microeconomía soportada empíricamente, con descripciones "realistas" del comportamiento de consumidores, empresas, bancos y mercados individuales. En opinión de Bergmann (2005, p. 55), el material disponible acerca del comportamiento de los negocios y de la economía en general -de lo cual depende el bienestar de la mayor parte de la población mundial-, producido por profesionales dentro de la corriente principal, diseminado en libros de texto, publicaciones especializadas, y enseñado en las principales facultades, "fue compuesto por economistas quienes se sentaron en su casa u oficina y... simplemente lo hicieron". Desde esta perspectiva, las teorías estándar sobre fijación de precios, planificación de la producción, toma de decisiones acerca de inversiones en planta y equipo, etc., no surgieron de la indagación directa a las personas encargadas de ejecutar tales acciones; en cambio, critica, fueron deducidas de una caracterización simple de aquello que se asumió como el medio en el cual debieron desenvolverse los hombres de negocios; esto acompañado por un conjunto de supuestos estandarizados de racionalidad y ambición humana. Bergmann (2005) recuerda a J. S. Mill (1843), para quien una ciencia tiene que contar con una teoría simple y elegante, y no ser, tan solo, una colección miscelánea de hechos. Empero, agrega Bergmann (2005, p. 57) 
Leyes científicas y predicción en ciencias sociales: una aproximación al caso de la economía

que "[...] si la teorización es hecha antes, durante, y/o después de la observación, esta no puede estar ausente en buena ciencia".

Según esta misma autora, los avances tecnológicos han permitido que ya no sea necesario construir modelos macroeconómicos sin información de magnitudes macrorreales. Ahora, indica, los modelos pueden ser construidos por computadoras capaces de representar hogares, empresas, bancos y agencias gubernamentales individuales, sus interacciones, y los flujos de fondos resultantes. La simulación, agrega Bergmann (2005, p. 61), permite realizar un seguimiento de aspectos importantes como los ingresos, capitales, deudas, reglas de decisión, posibilidades técnicas, historia, etc., de los individuos y las firmas. El punto es que las cantidades macro simuladas podrían ser derivadas con rigurosidad de las propensiones y actividades microeconómicas, al incorporar cualquier tipo de hábito -racional o no- detectado por observación directa, además de la inclusión de programas y regulaciones gubernamentales.

La construcción de una ciencia realista que describa el funcionamiento de la economía requeriría, de acuerdo con esta posición, de observaciones del comportamiento de los administradores en el desempeño de sus actividades. Para Bergmann (2005, p. 63) los economistas harían bien en adoptar la estrategia de los antropólogos - ir a vivir con la tribu que están estudiando y convertirse en participantes-observadores"-10.

Al respecto, bien vale recurrir de nuevo a la obra de Nagel (1961, p. 435), quien previene acerca de no caer en ninguno de dos extremos. Por una parte, (a) no se debe exagerar, en la línea de lo sostenido por Bergmann (2005), la capacidad humana de hacer conjeturas -es posible imaginar que se es un negociante de trigo y conjeturar acerca de la conducta probable al participar en un mercado fluctuante del mencionado producto-. Pero una conjetura no es un hecho y se puede fallar en la elección de los sentimientos o planes atribuidos al negociante o, aún coincidiendo, errar en la selección de los posibles cursos de acción. El otro extremo (b) consiste en minimizar la capacidad del científico social para explicar las acciones humanas sin que medie la experiencia, en sí misma, de los estados psíquicos atribuidos al sujeto bajo análisis. -Nagel (1961, p. 436) se pregunta: "¿debe un psiquiatra ser demente, al menos parcialmente, para estar en condiciones de estudiar al enfermo mental?"-.

10 Bergmann (2005, p. 63) rescata, como raro ejemplo de una intensa interacción entre un economista y hombres de negocios, la experiencia de Truman Bewley (1999). Este investigador entrevistó a más de tres mil administradores, y les preguntó por qué no bajaban los salarios durante una depresión -un asunto que ha sido objeto de 'especulación' entre los economistas-. Bewley(1999) identificó por lo menos veinticinco teorías publicadas al respecto. El hallazgo, contrario a veinticuatro de tales teorías, fue que, en opinión de los encargados de las empresas, reducir los salarios crearía severos problemas morales e interferiría con las operaciones de sus firmas.

Semestre Económico, volumen 16, №. 33, pp. 99-126 • ISSN 0120-6346, enero-junio de 2013, Medellín, Colombia 
En resumen, la capacidad del científico social para proyectarse a sí mismo, mediante la imaginación, en los fenómenos que trata de comprender, concierne a los orígenes de sus hipótesis, no a su validez. Alcanzar empatía con los actores de un proceso social puede ser heurísticamente importante para inventar hipótesis adecuadas del proceso; empero, según Nagel (1961, p. 437), "[...] su identificación empática con esos individuos no es, en sí misma, conocimiento". Tal identificación no anula la necesidad de elementos de juicio objetivos, evaluados de acuerdo con principios lógicos, comunes a toda investigación controlada, que apoyen su atribución de estados subjetivos a esos agentes.

\subsubsection{La teoría económica: ¿ciencia social o matemática formal?}

El filósofo de la economía, Alexander Rosenberg (1983), sostiene que desde el siglo XIX en economía se ha seguido una estrategia de investigación particular, idéntica en su forma a la que le dio paso desde el siglo XVI al acelerado desarrollo de las ciencias naturales. De acuerdo con Mirowski (1984), citado por Hollander, (1998, p. 170), por ejemplo, los adelantos acerca de la energía, ocurridos en la teoría física, influenciaron el surgimiento de la teoría económica neoclásica al proveer "la metáfora [de las fuerzas], las técnicas matemáticas y las nuevas actitudes hacia la construcción teórica". Para Alex Rosenberg (1992, p. 174), de otro lado, resultan notorias las características compartidas por la teoría económica y la teoría evolutiva: su compromiso con la optimalidad y la maximización, una consecuente similitud en el formalismo matemático y una apelación al equilibrio como la estrategia explicativa preferida. En tal sentido, el comportamiento que el economista busca explicar es considerado como el movimiento permanente de fuerzas reflexivas hacia un equilibrio estable que maximiza o minimiza alguna variable teórica crucial -la utilidad en microeconomía-. La estrategia imita las propias de la mecánica newtoniana y la teoría darwiniana de la selección natural; ello con la idea de que el éxito obtenido en estas debería reflejarse en la economía que las emula. Rosenberg (1983, p. 662) denomina a la anterior "estrategia extrema". En mecánica newtoniana, por ejemplo, "el comportamiento de un sistema siempre minimiza o maximiza las variables, reflejando los estados mecánicamente posibles del sistema" -en la teoría de la selección natural, por su parte, se maximiza la aptitud-. Su fuerza radica en que cuando la observación de un fenómeno difiere de lo predicho por la teoría extrema -newtoniana o darwiniana- no se asume de inmediato que esta ha sido falseada, sino que se ha podido fallar en la descripción de los elementos que en realidad operan en el sistema y la manera como ellos interactúan. Descubrimientos de nuevos planetas, instrumentos, leyes -como las de la termodinámica-, o del porqué de la persistencia de aparentes maladaptations -como la anemia de células falciformes-dan cuenta de su éxito. 
Leyes científicas y predicción en ciencias sociales: una aproximación al caso de la economía

No obstante, la analogía entre la economía y las -otras - teorías extremas solo pasaría, según Rosenberg (1983, p. 664), por el uso de la estrategia, ya que los frutos de la aplicación del programa de investigación no evidenciarían avances en algún grado equiparables a los de las mencionadas teorías de la naturaleza. Algunas falencias empíricas parecieran poner en entredicho buena parte del andamiaje de la economía. Antes, se habló de la indiferencia friedmaniana a la falsedad de los supuestos. A propósito, está claro que en economía, y en general en las ciencias, es necesario realizar abstracciones. Los modelos no pueden ser por completo idénticos a la realidad que pretenden describir; no obstante, de acuerdo con la fórmula del propio Friedman (1953), cabe recordar, existen criterios consistentes en la capacidad explicativa-predictiva de la teoría para evaluar su pertinencia. ¿Qué habría impedido, entonces, que, pese a seguir una estrategia similar a la de las ciencias naturales mencionadas, la teoría económica neoclásica lograra resultados equiparables? Pues bien, para Rosenberg (1983), los supuestos adoptados por la economía neoclásica, además de falsos, le dan forma a una teoría que explica y predice poco. Para este autor, el porqué de los fallos en economía se puede ubicar en aquello mismo que ha provocado la crisis en psicología. Según el propio Rosenberg (1983, p. 665), los filósofos han mostrado que el pensamiento ordinario y las ciencias del comportamiento -incluida la economía- describen las causas y efectos de la acción humana en términos que no son clases naturales ${ }^{11}$; no ofrecen clasificaciones que abarquen categorías de estados que compartan los mismos conjuntos de causas y efectos, así que no las pueden unir en generalizaciones causales que "mejoren nuestro nivel ordinario de predicción y control de las acciones humanas".

De acuerdo con el análisis de Marqués (2009), para Rosenberg (1992, p. 118), la respuesta para la anterior pregunta se halla en la existencia de problemas (a) en el tipo de conexión que la economía establece entre explanans y explanandum, y (b) en la naturaleza de sus variables explicativas mismas. En primer lugar, según él, la economía neoclásica intenta formalizar en una teoría de la elección racional-TER, en adelante- las explicaciones que de la acción humana ofrece el sentido común -más en concreto, aquello que se suele llamar "psicología popular"-. Para fijar su posición, Rosenberg (1998, p. 195) se vale de la siguiente analogía entre la ley de la sicología popular, "[L]: Si un agente desea el objetivo $\mathrm{O}$ y cree que la acción A es el mejor medio disponible para obtener $\mathrm{O}$, ceteris paribus el agente hará A", y la TER -que para este autor constituye el núcleo de la economía neoclásica-, la cual podría ser vista como

11 El término clase natural es complejo. Sin entrar en grandes discusiones, y a riesgo de pecar por sobresimplificación, es posible decir que una clase es natural si corresponde a un agrupamiento u ordenamiento que no depende, para su existencia, de los seres humanos. Por ejemplo, los elementos químicos y las partículas físicas suelen ser considerados clases naturales; mientras que, conjuntos conformados por "bromas de buen gusto" u "objetos útiles" no lo serían.

Semestre Económico, volumen 16, №. 33, pp. 99-126 • ISSN 0120-6346, enero-junio de 2013, Medellín, Colombia 
una versión más sofisticada de L, en la que conceptos como "creencia", "deseo" y "acción" han sido reemplazados por "expectativa", "preferencia" y "elección". Al parecer de Rosenberg (1998), L presenta inconvenientes insuperables y que también estarían presentes en la TER, a pesar de su aparente mejoramiento técnico con respecto a la primera. Para Rosenberg (1998, p. 196), citado por Marqués (2009, p. 378), el problema (a) radica en que

[...] una presunta ley que conecta preferencias y expectativas, de una parte, con sus efectos sobre la elección, por la otra, no puede ser testada. Debido a que no podemos establecer que su antecedente se cumple, excepto cuando ya conocemos que su consecuente ha ocurrido, la presunta ley es infalsable.

Según Marqués (2009, p. 378), Rosenberg (1998) considera que el tipo de conexión entre antecedente y consecuente, característico de la TER y de la "ley" L de sentido común, hace que resulte imposible contrastarlas, lo cual plantea interrogantes acerca de su contenido empírico y, sobre todo, acerca de la posibilidad de obtener el tipo de progreso predictivo sistemático que sería característico de las ciencias naturales.

El problema (b), por su lado, parecería ubicarse en la naturaleza misma de las variables consideradas. Marqués (2009, p. 378-380) explica la dificultad haciendo un paralelo con la ley de los gases. Se podría representar dicha ley de la siguiente manera:

$$
\text { LG: } V=c T / P
$$

En este caso, V representa el volumen de un gas cualquiera, T su temperatura, P es la presión ejercida sobre el gas, y c, una cierta constante. Dado el valor de la constante, es factible efectuar pronósticos acerca del volumen que adquirirá un gas cualquiera a partir de dos datos: la temperatura y la presión a la que se lo someterá. LG asume que T y P son los únicos factores causales en relación con el volumen del gas. Cualquier otro factor no mencionado puede ser considerado, de manera implícita, como irrelevante. De acuerdo con Rosenberg (1998), hay dos características que resultan decisivas para garantizar el poder predictivo de la ley. Una de ellas consiste en que se cuente con procedimientos independientes para medir los valores de las variables $-\mathrm{V}$, T y P-. La otra se trata de que la ley misma no sea utilizada en dichas mediciones (Marqués 2009, p. 378).

Es factible, por ejemplo, medir la temperatura de un gas mediante el procedimiento $\mathrm{X}$-no se requiere para ello conocer su presión o su volumen-. Luego se calcula su presión mediante otro procedimiento Y -en el que no es necesario contar con el dato de la temperatura obtenido con anterioridad-. Se remplazan los dos valores en la fórmula -LG-y se estima el valor de V-el volumen predicho-. Acto seguido, se mide el volumen del gas mediante otro procedimiento $Z$-que es diferente a los dos anteriores y en el cual no intervienen los datos arrojados en el cálculo de su 
Leyes científicas y predicción en ciencias sociales: una aproximación al caso de la economía

temperatura y presión, ni LG- el cual permite obtener el volumen "real" del gas. Al comparar luego ambos valores es posible determinar si la predicción obtenida a través de la ley es o no correcta. Este conjunto de procedimientos puede repetirse al variar T y $\mathrm{P}$ a voluntad, lo que permite obtener el número que se quiera de predicciones y registros (Marqués 2009, p. 379).

Lo anterior significa que es posible medir el valor de $\mathrm{V}$ con independencia de la estimación obtenida mediante el empleo de la ley LG y de los valores de T y P. - Si esto no fuera posible, dicha "ley" cesaría de ser una genuina hipótesis empírica; sería algo más cercano a una definición del volumen de un gas-. Para Rosenberg (1998), las características descritas son distintivas de las leyes científicas y dan cuenta tanto de su capacidad predictiva, como de su mejorabilidad. La mecánica del asunto consiste en el continuo afinamiento de las mediciones de las variables involucradas de tal forma que resulte viable rectificar la formulación original, reducir el margen de error y, al final, tras sucesivos ajustes, obtener predicciones cada vez más precisas (Marqués 2009, p. 379).

De hecho, en opinión de Rosenberg (1992, p. 124), la dificultad para la economía neoclásica está en que si se quiere aplicar, probar y mejorar las explicaciones hechas con la hipótesis de que los agentes toman decisiones racionales, es necesario fijar las condiciones iniciales pertinentes para la hipótesis. En ese orden de ideas, se requiere, con el ánimo de mejorar las predicciones, perfeccionar las mediciones de los estados del agente al cual se pretende aplicar la teoría con el objetivo de efectuar predicciones acerca de su comportamiento. Para que eso sea posible es necesario aplicar, probar y mejorar el equivalente -en una analogía con la termodinámica-a un termómetro, esto es, a algo que permita mensurar las condiciones iniciales a las cuales se va a aplicar la teoría de la elección racional. Sin embargo, ese "termómetro" debe ser independiente de la hipótesis, no debe depender de la verdad de dicha teoría. Pero de acuerdo con Rosenberg (1992, p. 126), acá es cuando de hecho fracasaría la teoría neoclásica:

[...] a causa de la naturaleza de los deseos, creencias y acciones [, n]o hay manera de decir lo que una persona cree a menos que ya sepamos lo que quiere o como actúa; no hay manera de decir lo que una persona quiere a menos que sepamos en lo que cree y cómo actúa; no hay manera de decir lo que una persona hará a menos que sepamos lo que quiere y cree. La única manera de que cualquier pareja de estos tres factores pueda conducirnos a una predicción acerca de la tercera es vía la teoría de la elección racional.

La teoría neoclásica se vería de esta manera atrapada en lo que algunos han denominado un círculo intencional ${ }^{12}$. En la exposición de Block (1981, p. 11-15) del

2 La intencionalidad es definida por Searle (2006, p. 221), como "la propiedad de la mente por la cual ésta se dirige, se refiere o alude a objetos y situaciones del mundo independientes de sí misma".

Semestre Económico, volumen 16, №. 33, pp. 99-126 • ISSN 0120-6346, enero-junio de 2013, Medellín, Colombia 
argumento tras la idea del círculo intencional -que Chisholm (1957) y Geach (1957) emplearon para atacar al conductismo-, este autor supone a un conductista quien analiza el deseo de alguien por un helado como su posesión de una serie de disposiciones como la de tomar un helado si se le es ofrecido uno. Pero alguien que quiere un helado estará dispuesto a tomarlo solo si sabe que ese es un helado verdadero -y no una clase de broma que se le quiere jugar con un objeto que se asemeja a un helado- y no cree que al tomarlo vaya a entrar en conflicto con otros deseos de mayor importancia para él -como, por ejemplo, el deseo de evitar la obligación de tener que regresar el favor-. En resumen, los conceptos intencionales siempre remiten a otros conceptos intencionales; no es posible definir un concepto intencional en términos de lo no-intencional. Por lo tanto, el balance para Rosenberg (1983, p. 665) es que las ciencias sociales -intencionales- se encuentran condenadas a quedar marginadas de cualquier esquema conceptual que identifique y sistematice los estados mentales y el comportamiento humano que describen y explican. Así, con respecto al caso de la economía, Rosenberg (1983, p. 664) se refiere en los siguientes términos:

\begin{abstract}
A pesar de su integridad conceptual, la microeconomía, junto con todas las ciencias de la acción humana y sus agregaciones, descansa en una falsa pero central convicción que vicia sus axiomas y así afecta los teoremas deducidos de ellos. La teoría económica asume que las categorías de preferencia y expectativa son las clases en las cuales las causas económicas deben ser sistematizadas, y que los eventos a ser explicados son apropiadamente clasificados en acciones como comprar, vender, y los movimientos de mercados, industrias, y economías en que estas acciones se agregan. La teoría ha hecho este supuesto, porque, claro está, es un supuesto que todos hacemos acerca del comportamiento humano; nuestro comportamiento constituye acción y es causado por la operación conjunta de nuestros deseos y creencias.
\end{abstract}

El resultado es el intento de formalizar tal concepción; así que la teoría del comportamiento del consumidor no sería otra cosa que la búsqueda de leyes que expresen la relación entre deseo, creencia y acción. La sentencia de Rosenberg (1983, p. 666) es lapidaria: si las variables que una teoría trata no son identificables con claridad ni mensurables -con creciente precisión-, entonces su capacidad explicativa-predictiva queda bloqueada. En este sentido, el intento por explicar el comportamiento humano a partir de creencias y deseos, y no el replicar la estrategia de las teorías extremas es aquello que daría cuenta del fracaso de la economía -y en general de las ciencias sociales-. Por todo lo dicho, y en el contexto de la reticencia de parte de los economistas a renunciar a su estrategia teórica -extremaintencional-, Rosenberg (1983) termina por concluir que la economía no sería como tal una ciencia empírica.

No se puede negar la existencia de múltiples teorías científicas, las cuales, a pesar de no lograr establecer el nivel clave de indagación, sirven como aproximaciones 
Leyes científicas y predicción en ciencias sociales: una aproximación al caso de la economía

útiles. ¿Habría, entonces, algún paralelo entre la economía y otras teorías -por ejemplo, las Leyes de Mendel, las que, a pesar de que su unidad de herencia no puede ser reducida al gen molecular, sirven como una aproximación bastante útil para la comprensión de ciertos fenómenos-? Al parecer no; la diferencia entre la economía y esas teorías científicas radica en que estas últimas han logrado un incuestionable éxito predictivo y un mejoramiento tecnológico del cual aquella carece, y que le ha impedido, por lo pronto, ir más allá de la formulación de predicciones de carácter cualitativo que no logran ser afinadas y de explicaciones retrospectivas que despiertan fuertes debates entre los economistas mismos.

Rosenberg (1983, p. 667), plantea que la teoría económica puede ser comparada, mejor que con la genética mendeliana, con la Teoría del flogisto, "cuyo fracaso se puede rastrear hasta su inconmensurabilidad con la teoría del oxígeno que la sustituyó". Así, añade el autor, el flogisto, al igual que las nociones intencionales, no son clases naturales -no existe tal cosa en la naturaleza-, por lo cual no se podría hablar de "teorías defectuosas" en cuanto a su metodología se refiere, sino, tan solo, falsas.

Un paralelo entre la geometría euclidiana y la teoría económica puede ser bastante ilustrativo. El surgimiento de la teoría general de la relatividad permitió comprender que la geometría euclidiana proporciona predicciones que divergen con respecto a la naturaleza: se trata, tan solo, de que no existe en la realidad alguna instanciación -alguna clase natural- de las formas geométricas contempladas en dicha teoría. Ahora bien, pregunta Rosenberg (1983): ¿es posible trazar un paralelo entre el Teorema de Pitágoras -aun cuando no existan triángulos o líneas rectas euclidianas- $y$, por ejemplo, la ley de la oferta y la demanda -sin importar que los seres humanos no sean agentes económicos dotados con una racionalidad perfecta-? La respuesta parece ser negativa: en el caso de la teoría económica no se cuenta, como en la física, con algo capaz de establecer -y explicar el porqué de- la divergencia entre el mundo físico y lo sostenido por la geometría euclidiana ${ }^{13}$.

¿Qué sucede entonces con la economía -neoclásica-? Para Rosenberg (1983, p. 672), esta habría renunciado a la pretensión de constituirse en una ciencia empírica para convertirse en una especie de rama de las matemáticas ubicada en una zona grisácea entre sistemas axiomáticos puros y aplicados ${ }^{14}$. Las implicaciones de la

13 Rosenberg (1983, p. 669) añade, además, que un papel como el de la física para la geometría podría ser desempeñado, para el caso de la economía, por alguna versión de la sicología cognitiva. Tal cosa sería "lógicamente posible" -no obstante, no se vislumbra con claridad en el horizonte científico más cercano-, y permitiría la conexión entre variables intencionales como 'preferencia' o 'expectativa' y estados sicológicos identificables de forma independiente.

14 Una rama de las matemáticas que para Rosenberg (1983, p. 672) se dedica "a examinar las propiedades formales de un conjunto de supuestos acerca de la transitividad de relaciones abstractas: axiomas que implícitamente definen una noción técnica de 'racionalidad,' tal como la geometría examina las propiedades formales de puntos y líneas 
valoración extendida por Rosenberg (1983) son fuertes, pues, como el mismo autor señala, la toma de decisiones en materia de política económica queda con un vacío grave en sus fundamentos. Tener claridad respecto a este diagnóstico es, a pesar de lo lúgubre que pueda llegar a ser, un buen punto de partida para la identificación de bases más sólidas sobre las cuales fundar una ciencia del comportamiento económico humano.

\section{4. ¿UNA O DOS CIENCIAS?}

\subsection{Tooby y Cosmides y la necesidad de la unificación de las ciencias}

Intentos por establecer leyes transculturales generales han aplicado conceptos por fuera de lo cultural, al acudir a variables referentes a factores físicos -como el clima-, biológicos -como los impulsos orgánicos-, psicológicos -como los deseos y actitudes-, económicos -como las formas de relaciones de propiedad-, sociológicos -como la cohesión social-. Hasta ahora tales intentos han sido infructuosos. El éxito de nuevos ensayos en esta dirección implicaría, para Nagel (1961, p. 420), emplear conceptos más abstractos, lógicamente separados de nociones populares, y servirse de mejores técnicas para la manipulación de conceptos en el análisis de fenómenos sociales reales.

Para Tooby y Cosmides (1992) los avances en biología evolutiva, ciencia cognitiva, ecología conductual, psicología evolucionista, antropología social y biológica, neurobiología, y el desarrollo de las computadoras posibilitaron la unificación de tres dominios que por tradición han sido separados: lo viviente, lo mental y lo humano, llevándolos al terreno analizable, desde una perspectiva científica, de la causación. En su concepción, las mentes, comportamientos, artefactos y culturas humanas son, todos ellos, fenómenos biológicos. Ignorarlo, en opinión de Tooby y Cosmides (1992, p. 20, 23), sería perpetuar una errada perspectiva dualista -propia de una versión "premoderna" de la biología-entre material/espiritual, cuerpo/mente, físico/mental, natural/humano, animal/humano, biológico/social, biológico/cultural.

Para estos dos autores, el balance de lo ocurrido desde el siglo XVIII en ciencias sociales es pobre. La razón, se aduce, es el predominio del denominado por ellos,

abstractos". Friedman (1953) no fue ajeno al fenómeno descrito. Para él, fruto de las dificultades en la comprobación de ciertas hipótesis económicas sustantivas, se produce una 'retirada' hacia el análisis puramente formal o tautológico. La lógica formal y las matemáticas son ayudas indispensables para contrastar la corrección de los razonamientos, descubrir las deducciones de las hipótesis y poder distinguir entre hipótesis alternativas. Sin embargo, Friedman (1953, p. 651) llama la atención para que la teoría económica no solamente describa sino que pueda predecir los resultados de las acciones humanas, tiene que ser algo más que un cúmulo de tautologías; "tiene que ser algo diferente de unas matemáticas disfrazadas". 
Leyes científicas y predicción en ciencias sociales: una aproximación al caso de la economía

Modelo estándar de las ciencias sociales -MEcs-, el cual habría clamado la autonomía de las ciencias sociales con relación a las demás ciencias. La alternativa, por su parte, la constituiría el Modelo causal integrado -MCI-, el cual según Tooby y Cosmides (1992, p. 23), "I... acepta y explota las conexiones naturales que existen entre todas las ramas de la ciencia, usándolos para construir un análisis cuidadoso de la interacción causal entre todos los factores que soportan un fenómeno. En este marco alternativo nada es autónomo y todos los componentes del modelo deben engranar".

Uno de los aspectos más importantes que el mci combate es la convicción del MECS de que aspectos culturales y sociales moldean, preceden y son externos al individuo; crean la mente humana -y no a la inversa-. La alternativa parte de que la arquitectura psicológica humana contiene mecanismos evolucionados, especializados en resolver problemas adaptativos de larga persistencia. Tales mecanismos imponen ciertos tipos de organización conceptual y de contenidos en la vida mental humana, los cuales le dan forma a la vida social y a aquello que es transmitido por medio de la cultura.

Para el MECS, la mente humana es como una especie de computadora multipropósito general con uno o pocos mecanismos que configuran la arquitectura mental. El MCI añade la existencia de varios mecanismos específicos -especializados en distintos conjuntos de problemas-. La creencia en una psique de propósito general es rebatida por cuanto todo su contenido debe provenir de fuera, de la cultura. Si algo es cultural debe ser maleable, y si es así no pueden ser formuladas leyes generales sólidas al respecto. Tal cosa es inaceptable para el proyecto científico tal y como lo conciben Tooby y Cosmides (1992, p. 42, 49).

Muy al contrario, la posibilidad de proporcionar modelos causales se halla, para estos autores (Tooby y Cosmides 1992, p. 47, 50), en el hecho de que un sistema social se asimila a un ecosistema, donde existen procesos de retroalimentación a partir de las propiedades dinámicas de sus componentes; en el caso de la sociedad, individuos humanos, de los cuales consideran posible elaborar modelos de su arquitectura psicológica -que no sería otra cosa que el fruto de procesos evolutivos adaptativos, de los que se podrían conocer los principios que les gobiernan-.

Comentan Tooby y Cosmides (1992, p. 52):

La teoría de la evolución por selección natural expandió vastamente el rango de cosas que podían ser explicadas, así que no solamente fenómenos físicos como las estrellas, cadenas montañosas, el impacto de los cráteres, y los abanicos aluviales, pudieron ser causalmente localizados y explicados, sino que también cosas como ballenas, ojos, hojas, sistemas nerviosos, expresiones emocionales, y la facultad del lenguaje.

Semestre Económico, volumen 16, №. 33, pp. 99-126 • ISSN 0120-6346, enero-junio de 2013, Medellín, Colombia 
A lo largo de este escrito se ha insistido en la importancia metodológica de la identificación del nivel de análisis adecuado para la construcción científica. Desde el punto de vista de Tooby y Cosmides (1992, p. 66-67), tal nivel debe ser aquel en el cual emerja lo invariante, el nivel del orden subyacente. En su opinión, aquello que son las matemáticas para la física lo son las descripciones de la ciencia cognitiva para el desarrollo de las ciencias del comportamiento; el éxito para descubrir la organización funcional de la mente humana radicaría en que dicha ciencia cognitiva sea complementada con los principios de la biología evolutiva.

La estrategia de investigación inserta en un análisis evolutivo funcional es bosquejado con las siguientes características: a) un objetivo adaptativo -una descripción de aquello que cuenta como resultado exitoso, desde un punto de vista biológico en una situación dada; esto es, preguntar cuál subconjunto, dentro del conjunto infinito, de secuencias conductuales potenciales contaría como solución al problema adaptativo-; b) condiciones antecedentes -las características del mundo ancestral deben contar con cierto grado de estabilidad que permita soportar la evolución de algún diseño producido dado un objetivo adaptativo determinado-; c) un diseño - una descripción de la organización articulada de características recurrentes en el organismo que en, su conjunto, abarca la -sospechada-adaptación-; d) un examen del desempeño - una descripción del resultado de la interacción entre la adaptación y el mundo; del rango de los resultados que el diseño genera en realidad-; e) una evaluación del desempeño -el análisis de lo bien que se las arregló el diseño para producir el objetivo adaptativo. Cuanto mejor sea el desempeño mayor será la probabilidad de que corresponda a una adaptación real-. La estrategia bosquejada tendría, de acuerdo con sus proponentes, como primer campo de aplicación la psicología, pero debería poder extenderse a todas las ciencias del comportamiento, incluida la economía.

Las arquitecturas fisiológicas y psicológicas del ser humano estarían constituidas, según los planteamientos de Tooby y Cosmides (1992, p. 89-99), por regularidades e imponen, dentro y entre culturas, toda clase de órdenes sobre la vida del hombre. Aquellas son mecanismos especializados que conocen cosas como emociones, expresiones faciales, el sentido de una situación particular para los demás, la organización subyacente a acciones sociales contingentes como amenazas, intercambios, lenguaje, motivación, etc. Dichos mecanismos habrían evolucionado con el objetivo de resolver problemas adaptativos en situaciones como la crianza de los hijos, las relaciones familiares, la elección de pareja, la atracción sexual, el evitar situaciones de peligro, el cuidado de la pareja, etc.

De momento, las aseveraciones de Tooby y Cosmides (1992) carecen de un respaldo empírico sólido, y no está del todo claro cómo incidirían tales mecanismos en 
Leyes científicas y predicción en ciencias sociales: una aproximación al caso de la economía

el comportamiento de un ser humano en calidad, por ejemplo, de agente económico. Lo planteado por ambos se presenta como una estrategia general de investigación, antes que como una teoría corroborada de manera suficiente. No se entiende bien, tampoco, cómo se agregarían los descubrimientos en el ámbito del individuo para responder por el conjunto social -en el caso de la economía, por la macroeconomía-. Si se recuerda lo expresado por Nagel (1961) acerca de la elección del nivel de indagación apropiado, resulta factible afirmar que la propuesta de estos dos autores es, por ahora, apenas una más; solo el tiempo y su éxito en la obtención de apoyo empírico permitirán establecer si se logran satisfacer los criterios empleados por la comunidad científica pertinente.

\subsection{Peter Winch y la autonomía de las ciencias sociales}

Los enfoques descritos con anterioridad, si bien son divergentes, coincidían en su convicción acerca de la conveniencia de contar con una ciencia social encaminada a la formulación de leyes generales y al logro de predicciones confiables. En esta sección se expone apenas una posición -aunque esta con seguridad se encuentra entre las más influyentes- que contraría la utilidad de dicho proyecto; esta es, la del filósofo wittgensteiniano Peter Winch (1958) en su obra The Idea of a Social Science and its Relation to Philosophy.

Para Winch (1958), la búsqueda de asimilar las ciencias sociales a las naturales ha limitado su propio desarrollo; algo que solo se podría remediar con una participación activa de la filosofía, que ligue la indagación sobre el entendimiento humano con el conocimiento de la naturaleza de la sociedad. La perspectiva que Winch (1958, p. 66) confronta es personificada en la figura de J. S. Mill, con lo cual espera cobijar tanto a sus seguidores como a sus reformadores, puesto que, en última instancia, todos acogerían la estrategia general -desarrollar ciencias sociales equiparables a las ciencias naturales desde el punto de vista metodológico-.

Para Mill (1843), inspirado en las ideas de Hume sobre causación, las condiciones de posibilidad para construir una ciencia dependen de la existencia de uniformidades del tipo: 'siempre que se presenta un evento A, este, de acuerdo con la experiencia, es seguido por eventos como B'. De allí que Winch (1958, p. 67-68) afirme que "[...] puede haber ciencia donde quiera que haya uniformidades; $y$ puede haber uniformidades incluso donde no las hemos descubierto aún y no estamos en posición de descubrirlas y formularlas en generalizaciones". Los fenómenos sociales no escaparían a tal posibilidad.

En la citada obra de Mill (1843) no existe diferencia lógica entre los principios que sirven para explicar cambios en la naturaleza y aquellos que explican cambios sociales. Aceptado esto, los elementos metodológicos se tornan empíricos -esperar 
y ver-. En su tradición wittgensteiniana, Winch (1958, p. 71) rechaza que el asunto apenas se trate de establecer cuál es la investigación empírica apropiada para explicar cierto fenómeno -no siempre tiene sentido decir cuál es la explicación causal de un fenómeno-, sino, desde la perspectiva del análisis filosófico, argüir qué tiene sentido decirse - a menudo es más fructífero comprender el significado de la acción humana-.

Establecer explicaciones causales en ciencias sociales no pasaría, entonces, por algo tan simple como reconocer que el grado de complejidad de aquello que ocurre allí es mayor que en los fenómenos naturales. Para Winch (1958, p. 72), la diferencia no sería de grado -como en el paso del agua líquida al hielo-, sino de clase-como en la distinción, sin gradaciones, entre estar vivo y estar muerto-. En el primer caso la experimentación es un buen método, en el otro el asunto es conceptual. De esta manera, describir un comportamiento como una serie de movimientos físicos arrojaría menos luz que explicar que aquello allí observado corresponde a, por ejemplo, el acto de orar a un dios y que este cumple un determinado papel dentro de una cultura particular.

Mill (1843) considera las explicaciones de las acciones en términos de los motivos del agente como una especie de explicación causal -existen versiones fisiológicas, como la de Newcomb y Charters(1952)-. Winch (1958) rechaza tal posición pues considera que bajo su lógica se llega a que, por ejemplo, el comportamiento que Shakespeare describe de Romeo se equipare al de una rata de laboratorio que sigue sus impulsos reproductivos. Por ello, para Winch (1958, p. 78), "[d]escubrir los motivos de una acción enigmática es incrementar nuestro entendimiento de esa acción; eso es lo que 'entendimiento' quiere decir como aplicado al comportamiento humano". Así, mientras el concepto de causa, propio de la óptica milliana, según el cual las acciones humanas y sus instituciones comprenden uniformidades factibles de ser explicadas en generalizaciones empíricas, hace parte del aprendizaje de una técnica para elaborar predicciones; el de motivo pertenecería al aprendizaje de los estándares que gobiernan la vida en sociedad; es solo en este contexto que un motivo puede lograr la inteligibilidad de un hecho pasado y futuro -por ejemplo, qué hizo o podría llegar a hacer una persona celosa-.

Al comparar su propósito -hacer inteligible- con el de Mill (1843) -explicar mediante leyes causales-, Winch (1958) sostiene que se trata de distintos tipos de explicación que no compiten entre sí. Sirven para propósitos distintos, responden a preguntas diferentes. Sin embargo, la comprensión de lo humano, de lo social, para Winch (1958) demanda una explicación de sentido que no se puede reducir a la explicación causal. 
Leyes científicas y predicción en ciencias sociales: una aproximación al caso de la economía

Por lo anterior, según Winch (1958, p. 87- 88), mientras que el científico natural trata tan solo con un juego de reglas, a saber, aquellas que gobiernan la misma investigación científica; aquello que el científico social estudia, tanto como su estudio de ello, son actividades humanas y, por lo tanto, regladas ${ }^{15}$. Sería un error, en principio, comparar la actividad de un estudiante de una forma de comportamiento social con la de un físico cuando estudia un sistema mecánico. El entendimiento del fenómeno social resultaría equiparable al entendimiento de un físico de la actividad de sus colegas, algo muy distante de lo que se podría decir a propósito del sistema mecánico. La necesidad de interpretación parece inevitable para las ciencias sociales en su búsqueda de una mejor comprensión de su objeto de estudio, algo que resulta innecesario en las ciencias naturales.

Por último, a propósito de la pregunta sobre la predicción, de si es posible o no en las ciencias de la sociedad, Winch (1958, p. 92) sostiene que si aquello que se busca es predecir tal como en las ciencias naturales, ello resulta, en una palabra, imposible. La predicción de decisiones humanas - que Winch (1958) cree viable hasta cierto punto- ${ }^{16}$ está abierta a una serie de alternativas posibles al aplicar cierta regla, de forma tal que un intento fallido de predicción no tiene que ser visto como un error del observador, sino que cabe la opción de que, de las diferentes vías de acción, se ha tomado otro de los tantos caminos potenciales; uno en principio distinto al contemplado en primera instancia. En la predicción científica el caso suele ser otro, ya que una predicción falseada a menudo implica algún tipo de error de parte del predictor: datos falsos o inadecuados, cálculos equívocos, defectos en la teoría o en los instrumentos de medición, etc.

Winch (1958, p. 92), al recordar a Maurice Cranston (1953), señala cómo predecir la escritura de una pieza poética o de un nuevo invento, implicaría escribir el poema o efectuar la invención misma, pero tal cosa no sería una verdadera predicción. En materia económica lo dicho valdría para fenómenos tan importantes como la innovación tecnológica y, en general, para toda estrategia y toma de decisión en un aspecto central del funcionamiento del capitalismo: la permanente competencia.

Lo planteado por Winch (1958) se puede relacionar con lo sostenido por Nagel (1961, p. 422) a propósito de las predicciones suicidas -nacen bien fundadas y, por ende, deberían confirmarse a futuro, pero debido a acciones emprendidas a consecuencia suya, terminan por ser anuladas-. Un ejemplo es que ante la advertencia de una

15 En el sentido de la interpretación hecha por Winch (1958, pp. 24-39) a propósito del análisis de Wittgenstein (2010) acerca del seguimiento de reglas.

16 Para Winch (1958, p. 92), "Si uno conoce la regla la cual alguien está siguiendo uno puede, en un número grande de casos, predecir qué hará él en circunstancias dadas. Por ejemplo, si O sabe que $\mathrm{N}$ está siguiendo la regla: 'Comienza con 0 y adiciona 2 hasta alcanzar 1.000', puede predecir que, habiendo escrito 104, N escribirá a continuación 106". 
caída en la economía, se toman medidas que, en última instancia, impiden que esta ocurra. Cosa contraria sucede con las profecías autorrealizadoras -nacen falsas, pero resultan verdaderas por las acciones emprendidas como consecuencia de creer en ellas-; por ejemplo, un pánico financiero infundado, el cual provoca retiros masivos de los ahorradores y causa una crisis real.

Nagel (1961) concuerda con Winch (1958) en que no es posible predecir cosas como la adquisición de conocimiento y las formas que este puede adoptar. Sin embargo, Nagel (1961, p. 425) anota que "[e]l punto en discusión es saber si es o no posible en principio, una vez adquirido un conocimiento de relaciones de dependencia entre fenómenos sociales, establecer leyes que tomen en cuenta las consecuencias que el uso de tal conocimiento puede tener para esas relaciones". El ejemplo de Nagel (1961) es que el hecho de que se sepa que un gas es mortal para el hombre, y que las personas por ello lo eviten, no refutaría la existencia de la ley.

\section{CONCLUSIONES}

A propósito del extenso debate relacionado con la posibilidad de que las ciencias sociales puedan, en algún momento de su desarrollo histórico, pasar de la formulación de generalizaciones estadísticas y la elaboración de predicciones cualitativas, a contar con leyes causales tales como las que han permitido a varias de las ciencias naturales explicar y predecir con resultados cada vez más precisos, este ensayo analiza una serie de argumentos provenientes de diferentes áreas del conocimiento para mostrar cómo la economía -esto es, la ciencia social de la cual a menudo se ha dicho que podría ser la primera en lograr el ideal para algunas corrientes de pensamiento, consistente en construir ciencias sociales equiparables a las naturales en cuanto a su metodología- habría fracasado en su intento de establecer las unidades de análisis básico con las cuales dar forma a sus teorías. En este caso, tal y como parece ocurrir con las ciencias del comportamiento humano en general, al recurrir a términos intencionales tales como expectativas, preferencias y elecciones, se habría bloqueado la posibilidad de efectuar mediciones y explicaciones por medio de leyes causales.

No es posible afirmar que, con lo dicho, se dé por concluido el debate general acerca de la equiparación metodológica de las ciencias. Persisten propuestas que con argumentos sugestivos, pero no corroborados a través de la experiencia, defienden o rechazan la conveniencia y viabilidad práctica de formular leyes científicas de la sociedad. En tal sentido, queda abierta la duda acerca de si el asunto es de carácter epistémico, es decir, algo que puede llegar a ser superado en la medida en que tengan lugar ciertos avances técnicos, tecnológicos y científicos -como el desarrollo de mejores formas e instrumentos de medición y de teorías- en otras 
Leyes científicas y predicción en ciencias sociales: una aproximación al caso de la economía

áreas del conocimiento; o se trata, en cambio de un asunto ontológico el cual resulta insuperable en tanto que los fenómenos estudiados por las ciencias naturales son de una clase -factible de ser explicada mediante leyes causales- diferente a la propia de los que interesan a los científicos sociales -los cuales a menudo implican la interpretación del comportamiento humano significativo; algo innecesario en las ciencias de la naturaleza más básicas-.

\section{BIBLIOGRAFÍA}

Bergmann, Barbara (2005). The Current State of Economics: Needs Lots of Work. En: Annals of the American Academy of Political and Social Science. Vol. 600, The Use and Usefulness of the Social Sciences: Achievements, Disappointments, and Promise, Julio, pp. 52-67.

Block, Ned (1981). Psychologism and Behaviorism. The Philosophical Review, XC, N. ${ }^{\circ}$, enero, pp. 5-43.

Comte, Auguste (1830-1842/1864). Cours de Philosophie Positive. Paris, Bachelier.

Cranston, Maurice (1953). Freedom: A New Analysis. Longmans, Green, 177 pp.

Chisholm, Roderick (1957). Perceiving. Ithaca, Cornell University Press, 203 pp.

Friedman, Milton (1953/2001). The Methodology of Positive Economics. En: L. McIntyre y M. Martin (Edits.), Readings in the Philosophy of Social Science. Cambridge, MIT Press, pp. 647-660.

Geach, Peter. (1957/1971) Mental Acts: Their Content and Their Objects. London, Routledge, 137 pp.

Hands, D. Wade (1993). Popper and Lakatos in Economic Methodology. En: U. Mäki, B. Gustafson, y C. Knudsen (Edits.), Rationality, Institutions and Economic Methodology. London, Routledge, pp. 61-75.

Hausman, Daniel (1998). Confirming Mainstream Economic Theory. En: Theoria, Vol, XIII, N. 32, pp. 261-278.

Hausman, Daniel (1984/2007). The Philosophy of Economics: An Anthology. Tercera ed. Cambridge, Cambridge University Press. 527 pp.

Hollander, Samuel (1995/2003). The Literature of Political Economy. New York, Routledge. 410 pp.

Klant, Johannes. (1994). The Nature of Economic Thought: Essays in Economic Methodology. Cheltenham, Michigan State University, $145 \mathrm{pp}$.

Mankiw, Gregory (2000). Macroeconomics. Cuarta ed. 553 pp.

Marqués, Gustavo (2009). Las epistemologías de la economía de Daniel Hausman y Alexander Rosenberg. Un análisis comparativo. En: J. García-Bermejo (Ed.), Sobre la economía y sus métodos. Madrid, Trotta, p. 367-382.

Marqués, Gustavo (2003). Qué aportan las consideraciones ontológicas al análisis económico. Una crítica al realismo crítico. En: G. Marqués, A. y. Ávila (Edits.), Objetividad, realismo y

Semestre Económico, volumen 16, №. 33, pp. 99-126 • ISSN 0120-6346, enero-junio de 2013, Medellín, Colombia 
retórica: Nuevas perspectivas en metodología de la economía. Madrid, Fondo de cultura económica, p. 35-62.

Mill, John Stuart (1843/1882). A System of Logic, Ratiocinative and Inductive, Being a Connected View of the Principles of Evidence, and the Methods of Scientific Investigation. New York, Harper \& Brothers, 1156p.

Mirowski, Philip. (1984). Physics and the 'Marginalist Revolution. Cambridge Journal of Economics, No 8, p. 361-79.

Nagel, Ernest (1961). The Structure of Science: Problems in the Logic of Scientific Explanation. New York, Harcourt, Brace and World, 618p.

Newcomb, T y Charters, W (1952). Social Psychology. London, Tavistock, 690p.

Rosenberg, Alexander (1992). Neo-Classical Economics and Evolutionary Theory: Strange Bedfellows? En: Proceedings of the Biennial Meeting of the Philosophy of Science Association, 174-183.

Rosenberg, Alexander (1992). Economics: Mathematical Politics or Science of Diminishing Returns? Chicago, The University of Chicago Press, 266p.

Rosenberg, Alexander (1983). If Economics Isn't Science, What Is It? En: M. Martin, \& L. McINtyre, Readings on the Philosophy of Social Science. Cambridge, The MIT Press, p. 661-674.

Rosenberg, Alexander (1998). Folk Psychology. En: J. Davis, D. Hands y U. Mäki (Edits). The Handbook of Economic Methodology. Cheltenham, Edward Elgar, p. 195-197.

Smith, Adam (1996 [1776]). La Riqueza de las naciones. Madrid, Alianza Editorial, 818p.

Tooby J. y Cosmides L. (1992). The Psychological Foundations of Culture. En: J. Barkow, L Cosmides \& J. Tooby (Edits.), The Adapted Mind. Evolutionary Psychology and the Generation of Culture. New York, Oxford University Press, 688p.

Winch, Peter (1958). The Idea of a Social Science and its Relation to Philosophy. London, Routledge \& Kegan Paul, 143p.

Wittgenstein, Ludwig (1953/2010). Philosophical Investigations. Singapore, John Wiley \& Sons, $592 p$. 